\title{
Effect of iron content on permeability and power loss characteristics of $\mathrm{Li}_{0.35} \mathrm{Cd}_{0.3} \mathrm{Fe}_{2.35} \mathrm{O}_{4}$ and $\mathrm{Li}_{0.35} \mathrm{Zn}_{0.3} \mathrm{Fe}_{2.35} \mathrm{O}_{4}$
}

\author{
VIVEK VERMA*, PRACHI SHARMA and ADARSH SINGH \\ Department of Physics, Hindu College, University of Delhi, Delhi 110 007, India
}

MS received 12 March 2013; revised 4 September 2013

\begin{abstract}
Substituted lithium ferrites having the chemical formula, $\operatorname{Li}_{0.35} C_{0.3} \mathrm{Fe}_{2.35} \mathrm{O}_{4}$ and $\mathrm{Li}_{0.35} \mathrm{Zn}_{0.3} \mathrm{Fe}_{2.35} \mathrm{O}_{4}$, with different iron (metal) contents $(2,4,6,8$ and 10$)$ in wt \% have been prepared by solid-state technique. Complex permeability and power loss of all samples have been measured by network analyser in the frequency range of $50-5000 \mathrm{kHz}$. Magnetic properties like saturation magnetization, coercivity, retentivity have been measured by vibrating sample magnetometer (VSM). The permeability of cadmium doped lithium ferrites exhibited higher values than zinc doped lithium ferrites. The power loss of cadmium doped lithium ferrites is lesser as compared to zinc doped lithium ferrites in the frequency range of 50-5000 $\mathrm{kHz}$ and at flux density of $10 \mathrm{mT}$. The behaviour of power loss with flux density has been found near about same for both series. Magnetic and power loss behaviour of the samples suggest that a small amount of Fe content can improve the properties of ferrite samples for microwave devices.
\end{abstract}

Keywords. Solid state technique; complex permeability; power loss; flux density.

\section{Introduction}

Lithium based ferrites have been used for cathode materials in lithium ion batteries (Dlpeeiotor and Dethackeray 1986), microwave applications (Nutan et al 2005) and memory core (Venudhar et al 2002), because of their high Curie temperature, high magnetization, excellent squareness of $M-H$ curve and good magnetic properties (Cho et al 1999; Yue et al 1999). In response to the current demand for size reduction of electronic devices, the development of compact and efficient switched-mode power supplies has received considerable attention. One way to achieve this is to use high switching frequencies which require low power loss cores to afford the transformation of high power (Verma et al 2006). The main types of losses encountered in ferrites are the eddy current loss, hysteresis loss and residual loss. Consequently the requirements of a power ferrite are high resistivity to keep the eddy current low, high permeability to reduce the residual losses, which consist mainly of resonance-relaxation losses. Additive materials can affect the magnetic properties, electrical properties and microstructure of ferrites by different mechanisms (Shokrollahi and Janghorban 2007; Verma et al 2008). Some additives such as $\mathrm{V}_{2} \mathrm{O}_{5}, \mathrm{Bi}_{2} \mathrm{O}_{3}$, etc act as grain growth accelerator by different mechanism like increasing the pore mobility due to the creation of excess cation vacancies. Other types of additives such as $\mathrm{SiO}_{2}, \mathrm{CaO}$, etc can create an electrical insulating film

*Author for correspondence (vermavivek.neel@gmail.com) around the grain and increase the resistivity of materials (Verma et al 2007). In the completely inverse ferrites such as $\mathrm{NiFe}_{2} \mathrm{O}_{4}$, large moments of the two $\mathrm{Fe}^{3+}$ sublattices cancel each other and no advantage is taken for the potential $\mathrm{Fe}^{3+}$ moment. In other ferrites like lithium ferrites in which $\mathrm{Fe}^{3+}$ on the two sublattices are disproportionate the large moment is used. Of course, these effects are not chemical (i.e. they are not related to $\mathrm{Fe}_{2} \mathrm{O}_{3}$ content) but crystallographic (i.e. they are related to lattice side distribution). Actually, with great variety of possible chemistries of spinel ferrites, $\mathrm{Fe}_{2} \mathrm{O}_{3}$ content of the finishing ferrite is varied least of all of the metal ions since it is pegged at 50 mole percent by the spinel formula $\left(\mathrm{MO} \cdot \mathrm{Fe}_{2} \mathrm{O}_{3}\right.$ ). In most commercially important $\mathrm{MnZn}$ ferrite materials, the starting mix may contain slightly $>50$ mole percent $\mathrm{Fe}_{2} \mathrm{O}_{3}$. The purpose of the extra iron is to improve the magnetic properties by the formation of $\mathrm{Fe}^{2+}$ ions.

Two compositions of substituted lithium ferrite is selected for our work because of their magnetic and dielectric properties (Bellad et al 2000; Yusoff and Abdullah 2003). This paper brings out the effect on magnetic properties and power loss of doping of iron metal by 2, 4, 6, 8 and $10 \mathrm{wt} \%$ in $\mathrm{Li}_{0 \cdot 35} \mathrm{Cd}_{0 \cdot 3} \mathrm{Fe}_{2 \cdot 35} \mathrm{O}_{4}$ and $\mathrm{Li}_{0 \cdot 35} \mathrm{Zn}_{0 \times 3} \mathrm{Fe}_{2 \cdot 35} \mathrm{O}_{4}$.

\section{Experimental}

Cadmium and zinc doped lithium ferrites, $\mathrm{Li}_{0.35} \mathrm{Cd}_{0.3}$ $\mathrm{Fe}_{2 \cdot 35} \mathrm{O}_{4}$ (LiCd ferrite) and $\mathrm{Li}_{0 \cdot 35} \mathrm{Zn}_{0 \cdot 3} \mathrm{Fe}_{2 \cdot 35} \mathrm{O}_{4}$ (LiZn ferrite) were prepared by conventional solid-state sintering technique from high purity oxides and carbonates of 
$\mathrm{Li}_{2} \mathrm{Co}_{3}, \mathrm{CdO}, \mathrm{ZnO}$ and $\mathrm{Fe}_{2} \mathrm{O}_{3}$. According to the stoichiometric compositions, $\mathrm{Li}_{0.35} \mathrm{Cd}_{0.3} \mathrm{Fe}_{2 \cdot 35} \mathrm{O}_{4}$ and $\mathrm{Li}_{0.35} \mathrm{Zn}_{0.3} \mathrm{Fe}_{2 \cdot 35} \mathrm{O}_{4}$, specified molar ratio of the iron oxide, lithium carbonate, cadmium oxide, zinc oxide were milled by wet grinding in power ball mill (RETCH, pm 400). Ball milled powder was pre-sintered at $750{ }^{\circ} \mathrm{C}$ for $10 \mathrm{~h}$. The pre-sintered powders were mixed with iron metal powder in 2, 4, 6, 8 and $10 \mathrm{wt} \%$ to form two different batches of LiCd and LiZn ferrites followed by final sintering at $1050{ }^{\circ} \mathrm{C}$ for $5 \mathrm{~h}$. Heating and cooling rates were controlled at $5{ }^{\circ} \mathrm{C} / \mathrm{min}$. The structural characterization of samples was carried out by X-ray diffraction $\left(\right.$ XRD Rigaku Miniflex II, step size $=0.02^{\circ}$ ) technique using $\mathrm{CuK} \alpha$ radiation (wavelength, $\lambda=1.5406 \AA$ ). A scanning electron microscope (SEM LEO 440) was used to observe microstructure details of the samples. Permeability values were measured by LCR meter (Agilent 4284 and 4285). Power loss values were measured by a B-H analyser (IWATSU, SY 8232). For permeability measurements, toroids were used having outer and inner radius 6 and $3 \mathrm{~mm}$, respectively. Magnetic measurements were performed for all samples at room temperature by plotting $\mathrm{M}-\mathrm{H}$ curves using vibrating sample magnetometer (VSM, Lake Shore 7304).

\section{Results and discussion}

Figures 1(a) and (b) show X-ray diffraction of iron metal doped LiCd and LiZn ferrites. The powder X-ray diffraction patterns exhibited that all the samples were identified as a single phase of cubic spinel structure.

Figure 2 shows scanning electron micrographs of lithium cadmium and lithium zinc ferrites with variation of iron content by wt\%. We observed some improvement in grain size with the variation of iron content in both soft ferrites. The average grain size of pure $\mathrm{Li}_{0 \cdot 35} \mathrm{Cd}_{0.3} \mathrm{Fe}_{3 \cdot 35} \mathrm{O}_{4}$ improved from $4 \mu \mathrm{m}$ with iron doping of $4 \mathrm{wt} \%$. But in the case of $\mathrm{Li}_{0.35} \mathrm{Zn}_{0.3} \mathrm{Fe}_{2 \cdot 35} \mathrm{O}_{4}$, there are two kinds of grain formation in pure sample as shown in figure 2(d). The average grain size of bigger and smaller grains of about 14 and $2 \mu \mathrm{m}$ are observed. On putting extra iron of $4 \mathrm{wt} \%$ in LiZn ferrite the grain size of smaller grains increases to $3 \mu \mathrm{m}$ and these decrease to $<2 \mu \mathrm{m}$ in case of $8 \mathrm{wt} \%$ sample.

Initial permeability response curves for LiCd and LiZn ferrites with different variation of iron in the frequency range $10^{5}-10^{8} \mathrm{~Hz}$ are shown in figure 3 . The frequency response of permeability shows a typical relaxation character, which may be due to reversible displacement of domain walls and also due to rotation of magnetization dipoles inside the domains. It is observed that the value of initial permeability (97) of pure lithium ferrite cadmium ferrite increases with iron concentration and attains a maximum value (137) for $4 \mathrm{wt} \%$ iron doped sample and starts to decrease with further increase in iron content. A similar behaviour is also found in case of lithium zinc ferrite as shown in figure 3(b). The permeability response for different compositions can be defined by the following relation (Huang et al 1994):

$$
\mu_{\mathrm{i}} \alpha \mu_{0} M_{\mathrm{s}}^{2} D_{\mathrm{m}} /\left[K_{1}+(3 / 2) \lambda_{\mathrm{s}} \sigma\right] \beta^{1 / 3} \delta,
$$

where $\mu_{\mathrm{i}}$ is the initial permeability, $M_{\mathrm{s}}$ and $D_{\mathrm{m}}$ are the saturation magnetization and average grain size, respectively. $K_{1}$ is the magneto-crystalline anisotropy, $\lambda_{\mathrm{s}}$ the saturation magnetostriction constant, $\sigma$ the inner stress, $\beta$ the volume concentration of impurity and $\delta$ the thickness of the domain wall.

The relationships between exciting flux densities and power loss Pcv at $50 \mathrm{kHz}$ of both series are shown in figure 4 . Power loss values increase obviously with exciting flux density for both samples. It is well known that $\mathrm{Pa}$ can be divided into hysteresis loss $(\mathrm{Ph})$, eddy current loss (Pe) and residulal loss (Pr). At high frequencies hysteresis
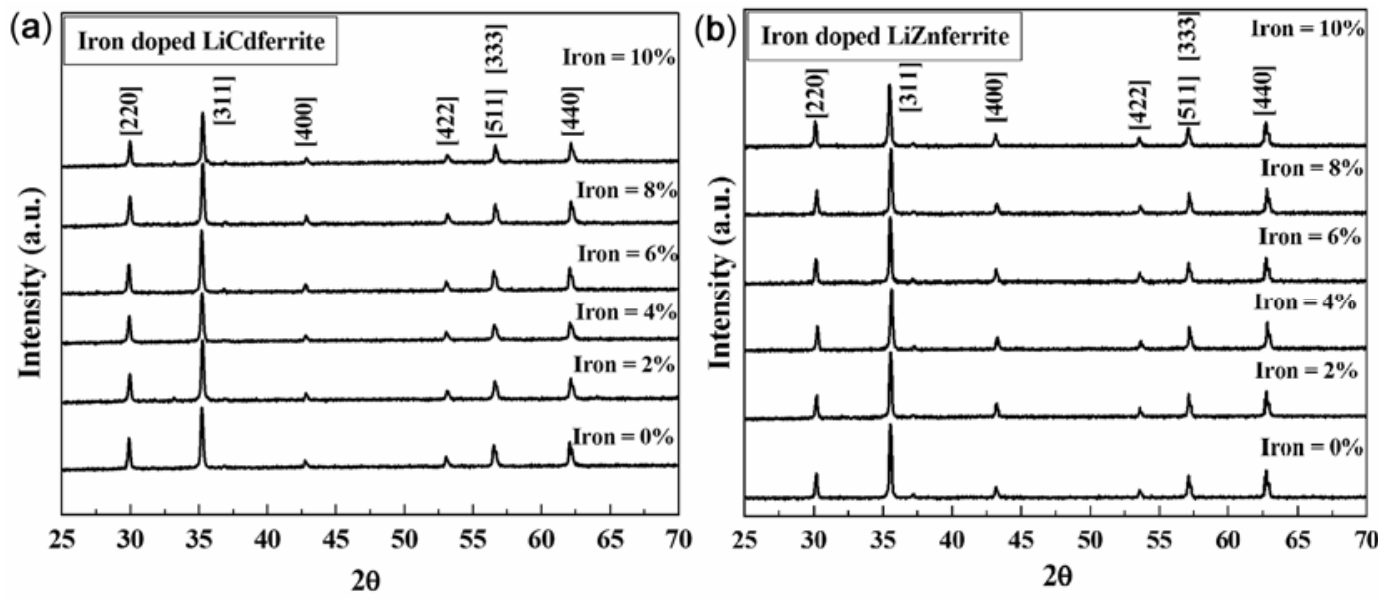

Figure 1. (a) X-ray diffraction pattern of iron doped lithium cadmium ferrite and (b) X-ray diffraction pattern of iron doped lithium zinc ferrite. 

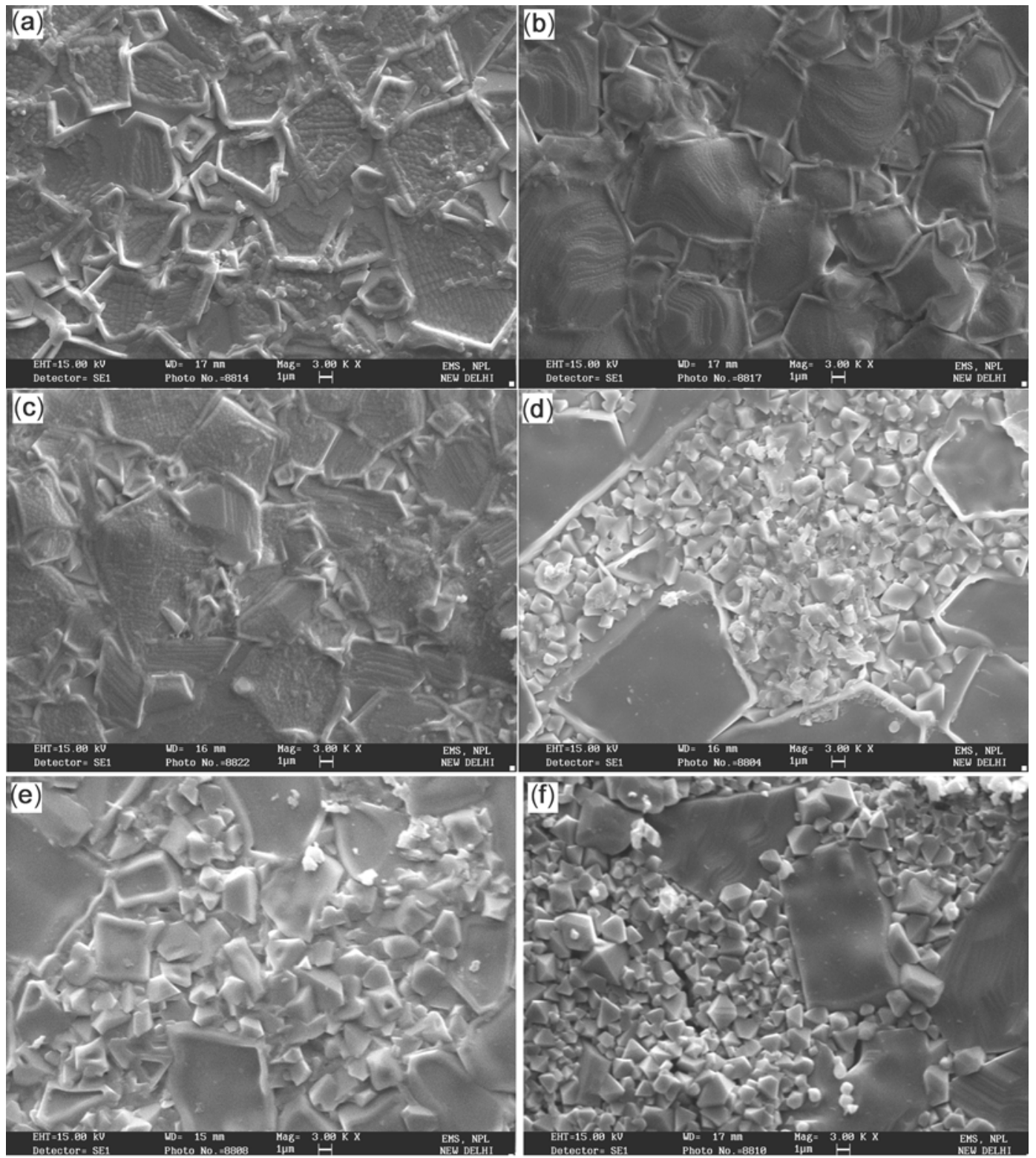

Figure 2. SEM micrographs of iron doped lithium cadmium ferrite (a) pure, (b) 4 wt\%, (c) 8 wt $\%$ and lithium zinc ferrite (d) pure, (e) $4 \mathrm{wt} \%$ and (f) $8 \mathrm{wt} \%$.
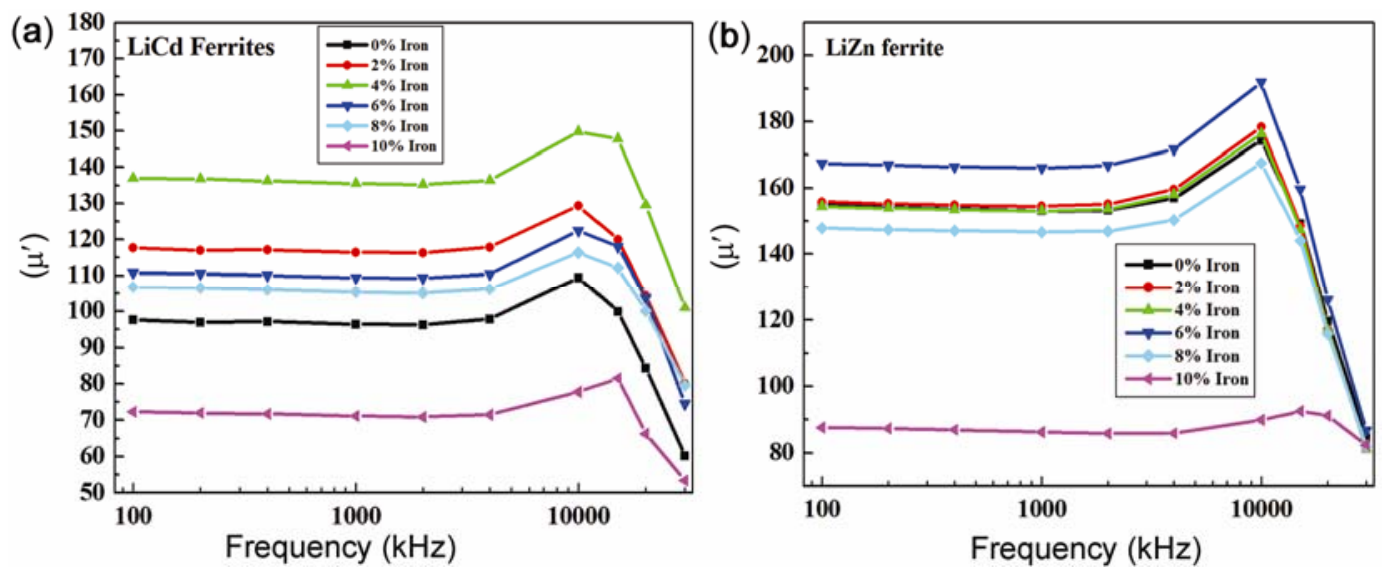

Figure 3. Permeability vs frequency of (a) $\mathrm{Li}_{0 \cdot 35} \mathrm{Cd}_{0.3} \mathrm{Fe}_{2 \cdot 35} \mathrm{O}_{4}$ and (b) $\mathrm{Li}_{0.35} \mathrm{Zn}_{0.3} \mathrm{Fe}_{2 \cdot 35} \mathrm{O}_{4}$ with different contents of iron. 

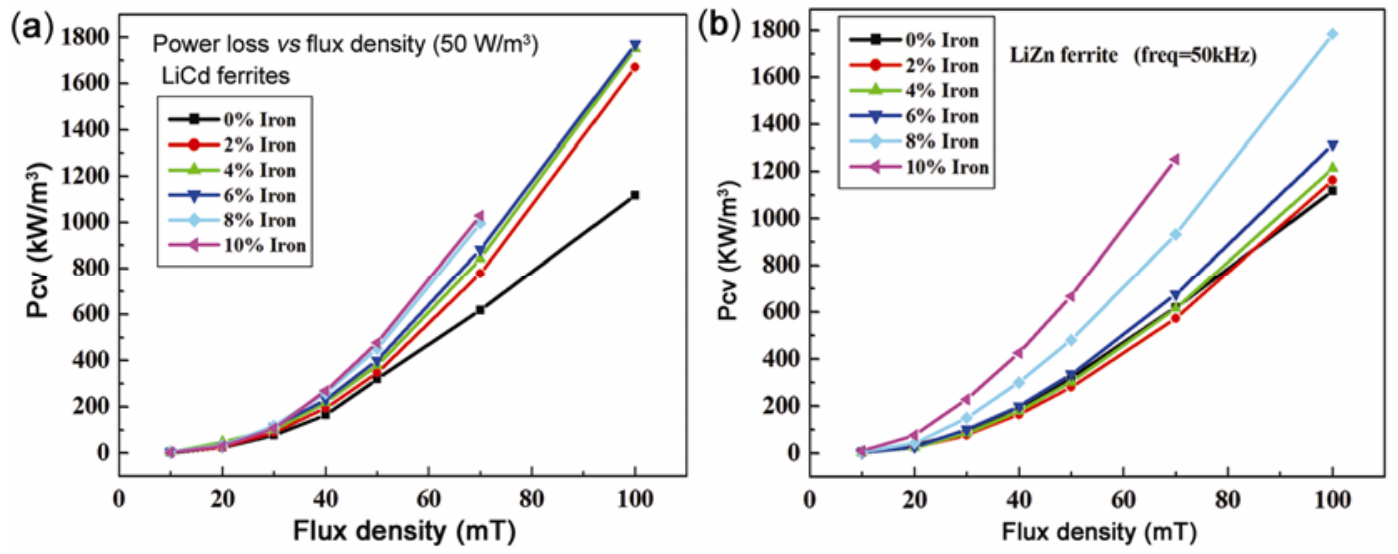

Figure 4. Power loss vs flux density at $50 \mathrm{kHz}$ of (a) $\mathrm{Li}_{0 \cdot 35} \mathrm{Cd}_{0 \cdot 3} \mathrm{Fe}_{2 \cdot 35} \mathrm{O}_{4}$ and (b) $\mathrm{Li}_{0.35} \mathrm{Zn}_{0.3} \mathrm{Fe}_{2 \cdot 35} \mathrm{O}_{4}$ with different contents of iron.
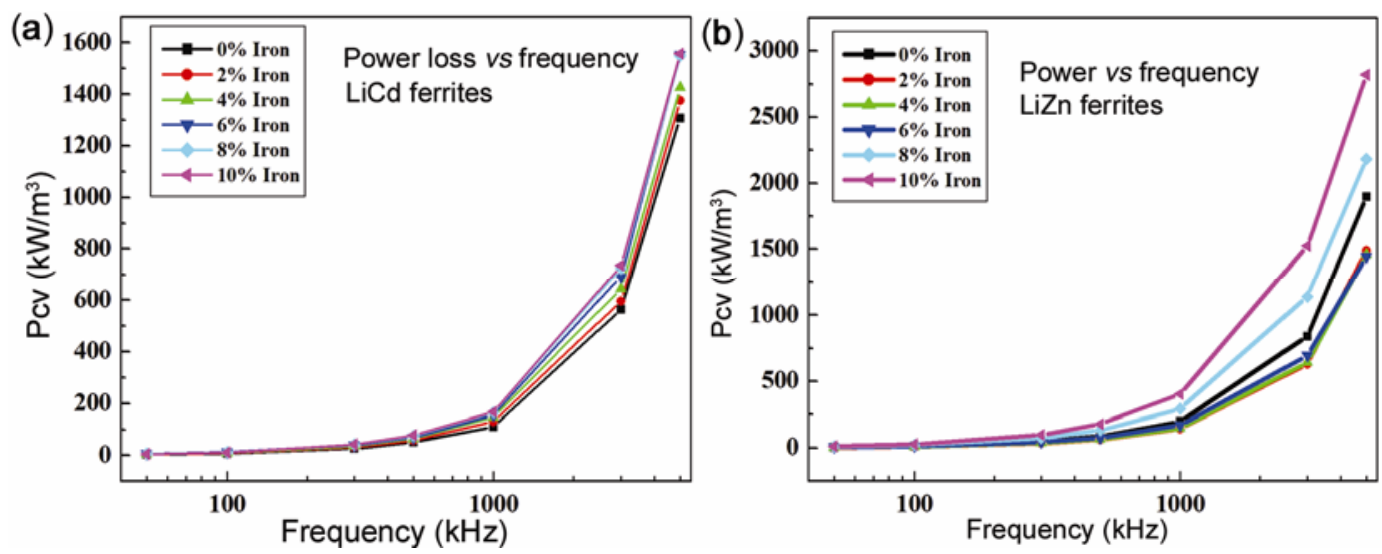

Figure 5. Power loss vs frequency at $10 \mathrm{mT}$ of (a) $\mathrm{Li}_{0 \cdot 35} \mathrm{Cd}_{0.3} \mathrm{Fe}_{2 \cdot 35} \mathrm{O}_{4}$ and (b) $\mathrm{Li}_{0 \cdot 35} \mathrm{Zn}_{0.3} \mathrm{Fe}_{2 \cdot 35} \mathrm{O}_{4}$ with different contents of iron.

loss is prominent in ferrites. Hysteresis loss can be expressed by (Hendricks et al 1991)

$$
\mathrm{Ph}=f \phi H \mathrm{~d} B,
$$

where $f$ is the frequency, $H$ the magnetic field strength and $B$ the magnetic induction. Magnetocrystalline anisotropy, magnetostriction, volume fraction of inclusions (pores, impurities and defects) and saturation magnetization are some properties of materials which influence the power loss of materials.

Low-hysteresis loss ferrites should have a high density, with the remaining porosity being located at the grain boundaries so as not to impede domain wall movement. Large and thin grain boundaries are advantageous for reduced interference with domain wall movement. Eddy current loss can be expressed as (Hendricks et al 1991):

$$
\mathrm{Pe}=C B^{2} f^{2} d^{2} / \rho,
$$

where $C$ is the proportionality constant, $B$ the flux density, $f$ the frequency, $\rho$ the resistivity and $d$ the thickness of the material. Eddy current loss can be reduced by increasing the resistivity of the polycrystalline ferrite by increasing grain boundary resistivity.
Frequency dependence of power loss for both series in frequency range $100 \mathrm{kHz}-5 \mathrm{MHz}$ at the exciting condition of $\mathrm{Bm}=10 \mathrm{mT}$ are shown in figures 5(a) and (b). The power loss has remained low for all the samples up to $1 \mathrm{MHz}$ beyond which it has been observed to increase rapidly.

\section{Conclusions}

We find that some extra amount of iron in $\mathrm{Li}_{0.35} \mathrm{Cd}_{0.3}$ $\mathrm{Fe}_{2 \cdot 35} \mathrm{O}_{4}$ and $\mathrm{Li}_{0.35} \mathrm{Zn}_{0 \cdot 3} \mathrm{Fe}_{2 \cdot 35} \mathrm{O}_{4}$ seems to have produced better permeability and microstructure. These ferrites have low power loss up to $1 \mathrm{MHz}$ frequency and therefore these ferrites are suitable for power applications in this frequency range.

\section{Acknowledgement}

The authors are grateful to the Director, National Physical Laboratory, New Delhi, India, for providing measurement facilities to carry out this work. 


\section{References}

Bellad S S, Watawe S C, Shaikh A M and Chougule B K 2000 Bull. Mater. Sci. 2383

Cho Y S, Burdick Y L and Amarakoon V R W 1999 J. Am. Ceram. Soc. 821416

Dlpeeiotor A and Dethackeray M M 1986 Mater. Res. Bull. 21 583

Hendricks C R, Amarakoon V W R and Sullivan D 1991 Ceram. Bull. 70817

Huang Y J, Li S K and Ian Z W 1994 Magn. Mater. (Beijing: Publishing House of Electronics Industry) p. 48

Nutan Gupta C, Kashyap, Subhash and Dube D C 2005 J. Magn. Magn. Mater. 288307
Shokrollahi H and Janghorban K 2007 Mater. Sci. Eng. B141 91

Venudhar Y C and Mohan K Satya 2002 Mater. Lett. 54135

Verma Anjali, Alam M I, Chatterjee Ratnamala, Goel T C and Mendiratta R G 2006 J. Magn. Magn. Mater. 300500

Verma Vivek, Pandey Vibhav, Kotanala R K, Kishan Hari, Kumar Nitender and Kothari P C 2007 J. Alloys Compd. 443 178

Verma Vivek, Gairola S P, Pandey Vibhav, Kotanala R K and Su Hua 2008 Solid State Commun. 148117

Yue Z X, Li L T, Zhou J, Zhang H G and Gui Z L 1999 Mater. Sci. Eng. B64 68

Yusoff A N and Abdullah M H 2003 Mater. Sci. Eng. B99 278 